\title{
Sulfonation of Poly(phenylene oxide) Anion Exchange Membrane for All Vanadium Flow Redox Battery
}

\author{
Nanfang Wang ${ }^{1, *}$, Fan Zhang ${ }^{1}$, Ru Zhang ${ }^{1}$, Wenchang Zhou ${ }^{1}$, Dan Lu ${ }^{2}$ \\ ${ }^{1}$ Hunan Provincial Key Laboratory of Environmental Catalysis \& Waste Recycling, School of \\ Chemistry and Chemical Engineering, Hunan Institute of Engineering, Xiangtan 411104, China \\ ${ }^{2}$ Hunan Corun New Energy Co., Ltd., Changsha 410205, China \\ *E-mail: cdwnf@126.com
}

doi: $10.20964 / 2019.06 .39$

Received: 4 February 2019 / Accepted: 28 March 2019 / Published: 10 May 2019

To develop a low cost non-fluorinated membrane for vanadium redox flow battery (VRFB), several commercial ion exchange membranes (IEM) were compared in terms of primary properties such as ion exchange capacity (IEC), vanadium ion permeability $(P)$ and water transfer $(W T)$ and chemical stability, and an anion exchange membrane (AEM) DF-a (based on Poly(phenylene oxide) polymers) was sulfonated into amphoteric ion exchange membranes (DF-a1 and DF-a2) to restrain WT. Effects of sulfonation on morphologies, selective proton conductivity $(\sigma), W T$ and chemical stability of membranes were investigated. The results showed that sulfonation can improve $I E C, \sigma$, Selectivity and chemical stability of the AEM (DF-a). Due to Donnan effect, DF-a2 had a more dramatic reduction in $W T$ and self discharge in VRFB than DF-a. Cell test showed that the membrane DF-a2 had higher coulombic efficiency $(C E)$ and energy efficiency $(E E)$ than DF-a and DF-a1, possessing a better potential application in VRFB.

Keywords: Amphoteric membrane; Sulfonation; Vanadium permeability; Water transfer; Vanadium redox flow battery

\section{FULL TEXT}

(C) 2019 The Authors. Published by ESG (www.electrochemsci.org). This article is an open access article distributed under the terms and conditions of the Creative Commons Attribution license (http://creativecommons.org/licenses/by/4.0/). 